Journal of Agrometeorology 23 (4) : 375-380 (December 2021): https://doi.org/10.54386/jam.v23i4.140

\title{
Sensitivity analysis of WOFOST for yield simulation of cassava over the major growing areas of India
}

\author{
RAJI PUSHPALATHA ${ }^{1}$, GOVINDAN KUTTY ${ }^{2}$ and BYJU GANGADHARAN ${ }^{*}$ \\ ${ }^{I} I C A R$ - Central Tuber Crops Research Institute, Thiruvananthapuram, India \\ ${ }^{2}$ Indian Institute of Space Science and Technology, Thiruvananthapuram, India \\ *Corresponding author email : byju.g@icar.gov.in
}

\begin{abstract}
A study was conducted to assess the meteorological sensitivity of the WOFOST crop model in simulating the yield of cassava. The sensitivity was designed by changing the present meteorological data by \pm 1 to $\pm 5 \%$. The results has shown the minimum temperature influencing the yield of cassava (variation: 4.94 to $-7.65 \%$ ) followed by the maximum temperature (yield variation: 6.39 to $-6.03 \%$ ) and solar radiation (yield variation: -2.41 to $2.07 \%$ ). The trends of these meteorological variables have been further analyzed over the major cassava growing regions in India to link its variations with cassava production. A significant trend has been detected during the monsoon season in northeast India, with a decadal change of $0.63^{\circ} \mathrm{C}$. At the same time, a significant trend was detected in the peninsular region during the winter season, with a value of $0.74^{\circ} \mathrm{C} /$ decade. The rate of solar dimming in northeast India during the monsoon season was -0.53 hour/decade and during the autumn season, it was -0.25 hour/decade, respectively. The meteorological sensitivity of crop model on its yield and trends may assist the decision-makers in developing appropriate plans mitigations strategies to enhance crop production to ensure food security.
\end{abstract}

Key words: Sensitivity, WOFOST, NASA POWER, cassava, yield prediction, heat stress

Crop yield estimations at the field level are laborious and time-consuming, and the crop models are the better choice in such cases to estimate the crop growth and yield parameters. The crop modeling in data-sparse regions is one of the challenges for research workers, and such situations may be overcome by the spatial interpolation of available gridded global weather data. The accuracy and dependency of these data has always been a concern among researchers to model the crop yield in context of food security and climate change. The difference in meteorological input for a specific location can produce very different outputs for that particular crop (Zare et al., 2016; Borkakati et al., 2021; Sreenivas et al., 2021). Therefore, it is necessary to identify the influence of each meteorological input parameters into a crop model to ensure accuracy in the model output. Sensitivity analysis (SA) is widely used to determine the effect of each input parameter on model output, and this identifies the contribution of each parameter to the model's response (Richtera et al., 2010).

Cassava (Manihot esculenta Crantz) is one of the major tropical root crops, and it is being considered a food security crop (Pushpalatha and Byju, 2020) in context of ensuing climate change and variability. The mineral nutrition of cassava makes this crop equally competitive as that of the major food grain crops with higher productivity (Byju and Suja, 2020). However, limited modelling studies are available for this crop in India. The present study analyzes the meteorological sensitivity of the crop model WOFOST (Boogaard et $a l ., 1998)$ in simulating the cassava yield, followed by the trend analysis of meteorological parameters such as minimum and maximum temperatures, sunshine duration/ radiation over the major cassava growing areas in India.

\section{MATERIALS AND METHODS}

\section{Meteorological data and study locations}

The gridded data of daily maximum and minimum temperatures available at $1^{\circ}$ resolution from 1980 to 2010 (http://www.imdpune.gov.in/library/Data_Sale.html) has been used for the trend analysis. The sunshine duration (a 
proxy for radiation) for the given period has been derived from ERA-Interim 6-hourly surface reanalysis from the European Center for Medium-Range Weather Forecasting (ECMWF， http://apps.ecmwf.int/datasets/data/interimfull-daily/levtype $=$ sfc $)$. The data has been derived using the Gridded Data and Analysis System (GrADS) software. The sensitivity analysis was conducted at ICAR-Central Tuber Crops Research Institute, Thiruvananthapuram, Kerala, one of India's major cassava growing locations. The trend analysis of these meteorological variables has also been conducted over major cassava growing regions in India such as northeast $\left(22^{\circ}-29^{\circ} \mathrm{N} ; 88^{\circ}-96^{\circ} \mathrm{E}\right)$ and peninsular $(\mathrm{P})\left(8-21^{\circ} \mathrm{N}\right.$ latitude; $72^{\circ}-87^{\circ} \mathrm{E}$ longitude $)$ regions.

\section{Model calibration and meteorological sensitivity}

WOrld FOod STudies (WOFOST), a growth and yield simulation model for annual crops, was used in this sensitivity study, and its structure has been comprehensively described in Boogaard et al. (1998). The meteorological variables required for the model are solar radiation, $\mathrm{RAD}\left(\mathrm{kJ} \mathrm{m}^{-2} \mathrm{day}^{-1}\right)$, maximum and minimum temperatures $\left({ }^{\circ} \mathrm{C}\right)$, vapour pressure, e $(\mathrm{kPa})$, wind velocity, $\mathrm{u}\left(\mathrm{m} \mathrm{s}^{-1}\right)$ and rainfall, $\mathrm{RF}(\mathrm{mm})$. The model was calibrated using the previously recorded crop data under the All India Coordinated Research Project on Tuber Crops (Pushpalatha et al., 2021). The growth and yield data of H-226, a long duration (10 months) variety of cassava, was used in this study to calibrate the WOFOST model. The extent of meteorological sensitivity of WOFOST on yield simulations was assessed by designing sensitivity by changing the values from \pm 1 to $\pm 5 \%$ of the observational data collected from the observatory of ICAR-Central Tuber Crops Research Institute (ICARCTCRI), Thiruvananthapuram, Kerala, India.

\section{Trend analysis of meteorological variables}

The Mann-Kendall (MK) trend analysis (Mann, 1945; Kendall, 1975) was used to identify the seasonal (winter- DJF; summer-MAM; monsoon-JJAS; autumn$\mathrm{ON}$ ) and monthly trends in sunshine duration (a proxy for radiation), maximum and minimum temperatures over northeast and peninsular regions in India. The MK test has been widely used to evaluate trends in time series analyses in agro-meteorological data sets (Singh et al.,
2021). Following the trend detection, the rate of decadal change in sunshine duration and temperature (seasonal and monthly values) has been derived by multiplying the value of the slope of the time series with the total length of the available data used for the analysis.

\section{RESULTS AND DISCUSSION}

\section{Assessment of meteorological sensitivity of WOFOST to crop yield}

The air temperature viz., minimum (Tmin) and maximum temperatures (Tmax) and solar radiation happen to be important variables influencing the cassava yield. While using WOFOST for sensitivity analysis, changes in minimum temperature (Fig 1) in the magnitude of $1.89{ }^{\circ} \mathrm{C}\left(-1.16{ }^{\circ} \mathrm{C}\right)$ has affected the corresponding yield of cassava in the magnitude of $-7.65 \%$ (4.94 \%), respectively. An increase in the minimum temperature $\left(>25{ }^{\circ} \mathrm{C}\right)$ from the current value $\left(\right.$ mean $\left.\operatorname{Tmin}=23.23{ }^{\circ} \mathrm{C}\right)$ caused a reduction in the cassava yield due to heat induced stresses. The sensitivity on decreasing magnitudes of minimum temperature upto $15{ }^{\circ} \mathrm{C}$ indicated an increase in the cassava yield. Similar on the pattern, an increase in maximum temperature $\left(1.57^{\circ} \mathrm{C}\right)$ reduced the crop yield $(-6.03 \%)$ while decrease in maximum temperature (-1.26 ${ }^{\circ} \mathrm{C}$ ) increased the yield by $6.39 \%$ (Fig. 2) up to $25{ }^{\circ} \mathrm{C}$ at the current location. The per cent changes in cassava yield due to variations in solar radiation has been less (Table 1) when compared with temperature (minimum and maximum) induced changes. Though, the crop yield variations ranged between to 2.07 to 2.41 per cent with the changes in solar radiation $( \pm 5 \%)$ of its mean present value.

\section{Temporal trends in meteorological variables over the major cassava growing regions}

Maximum temperature in the northeast and peninsular regions indicated increasing trend in all the four seasons (Table 2). However, a significant trend was detected only during monsoon season in northeast region with a decadal change of $0.63^{\circ} \mathrm{C}$. At the same time, a significant trend was detected in peninsular region during the winter season with a value of 0.74 ${ }^{\circ} \mathrm{C} /$ decade. An increasing trend in seasonal minimum temperature was observed in the both the regions, and 
Table 1: Sensitivity of solar radiation of cassava yield

\begin{tabular}{lll}
\hline \% change & $\begin{array}{l}\text { Average RAD } \\
\left(\mathrm{MJ} \mathrm{m}^{-2} \text { day }^{-1}\right)\end{array}$ & $\begin{array}{l}\text { Yield } \\
\left(\mathrm{t} \mathrm{ha}^{-1}\right)\end{array}$ \\
\hline-5 & 17216 & 36.58 \\
-4 & 17398 & 36.77 \\
-3 & 17579 & 36.96 \\
-2 & 17760 & 37.14 \\
-1 & 17941 & 37.32 \\
Base & 18122 & 37.49 \\
1 & 18304 & 37.65 \\
2 & 18485 & 37.81 \\
3 & 18666 & 37.97 \\
4 & 18847 & 38.12 \\
5 & 19029 & 38.26 \\
\hline
\end{tabular}

Table 3: Trend and decadal changes in monthly values of Tmax and Tmin ( ${ }^{\circ} \mathrm{C} /$ decade $)$

\begin{tabular}{lllll}
\hline \multirow{2}{*}{ Month } & \multicolumn{2}{c}{ Northeast } & \multicolumn{2}{c}{ Peninsular } \\
\cline { 2 - 5 } & Tmax & Tmin & Tmax & Tmin \\
\hline January & 0.15 & 0.78 & $0.84^{*}$ & -0.31 \\
February & 1.29 & 1.36 & 0.78 & 0.06 \\
March & 1.44 & $1.30^{*}$ & 0.50 & 0.19 \\
April & 0.12 & $1.36^{*}$ & 0.25 & 0.19 \\
May & 0.93 & $1.27^{*}$ & -0.22 & -0.09 \\
June & -0.03 & 0.50 & 0.28 & 0.16 \\
July & 0.81 & $0.99^{*}$ & 0.12 & 0.22 \\
August & 0.48 & $0.84^{*}$ & 0.40 & 0.19 \\
September & $1.17^{*}$ & $0.96^{*}$ & 0.00 & 0.16 \\
October & 0.33 & $1.12^{*}$ & 0.00 & 0.19 \\
November & 0.00 & $1.58^{*}$ & $0.59^{*}$ & 0.81 \\
December & 0.39 & $1.24^{*}$ & 0.68 & -0.16 \\
* denotes trend detected at 5\% significance level using \\
Mann-Kendall trend analysis where p $<0.05$ and '-' sign \\
indicates decreasing trend
\end{tabular}

Table 2: Trend and decadal changes in Tmax and Tmin ( $\mathrm{C}$ decade)

\begin{tabular}{|c|c|c|c|c|c|c|c|c|}
\hline \multirow{2}{*}{ Region } & \multicolumn{2}{|c|}{ Winter } & \multicolumn{2}{|c|}{ Summer } & \multicolumn{2}{|c|}{ Monsoon } & \multicolumn{2}{|c|}{ Autumn } \\
\hline & Tmax & Tmin & Tmax & Tmin & Tmax & Tmin & Tmax & Tmin \\
\hline \multirow{3}{*}{ Northeast } & 0.63 & $1.15^{*}$ & 0.84 & $1.33^{*}$ & $0.60^{*}$ & $0.81^{*}$ & 0.18 & $1.36^{*}$ \\
\hline & -0.14 & -0.36 & -0.2 & -0.47 & -0.29 & -0.45 & -0.08 & -0.4 \\
\hline & $0.30^{* *}$ & $0.00^{* *}$ & $0.13^{* *}$ & $0.00^{* *}$ & $0.02^{* *}$ & $0.00^{* *}$ & $0.54^{* *}$ & $0.00^{* *}$ \\
\hline \multirow{3}{*}{ Peninsular } & $0.74^{*}$ & $-0.12^{*}$ & 0.16 & 0.09 & 0.22 & 0.19 & 0.28 & 0.5 \\
\hline & -0.36 & -0.33 & -0.06 & $(-0.10)$ & -0.13 & -0.05 & -0.19 & -0.17 \\
\hline & $0.00^{* *}$ & $0.00^{* *}$ & $0.63^{* *}$ & $0.44^{* *}$ & $0.33^{* *}$ & $0.74^{* *}$ & $0.14^{* *}$ & $0.19^{* * *}$ \\
\hline
\end{tabular}

* denotes trend at 5\% significance level using Mann-Kendall trend analysis where $\mathrm{p}<0.05$; value in bracket denotes the test statistic value obtained through MK test; ** denotes the p value obtained in the MK-test; '-‘ sign indicates decreasing trend.

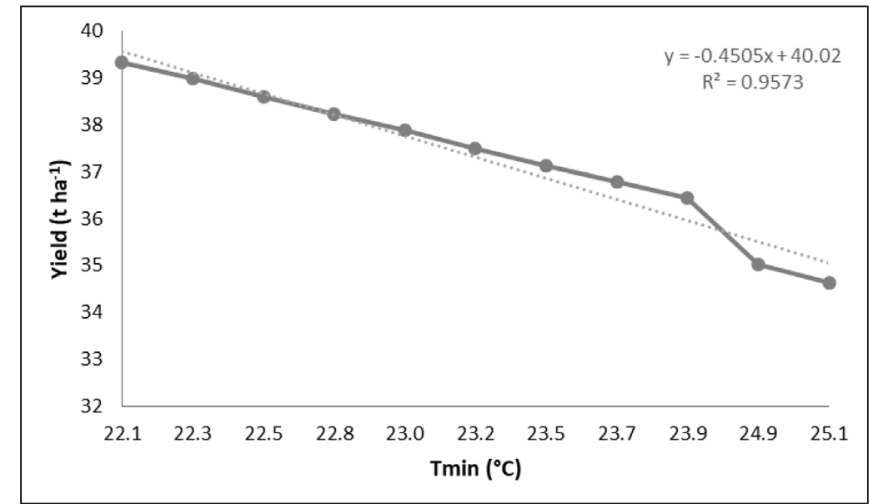

Fig. 1: Predicted yield of cassava with respect to the sensitivity of minimum temperature

the trends were found to be statistically significant by MK-test at a 95\% confidence level. The trend observed in northeast region was stronger with variability ranging

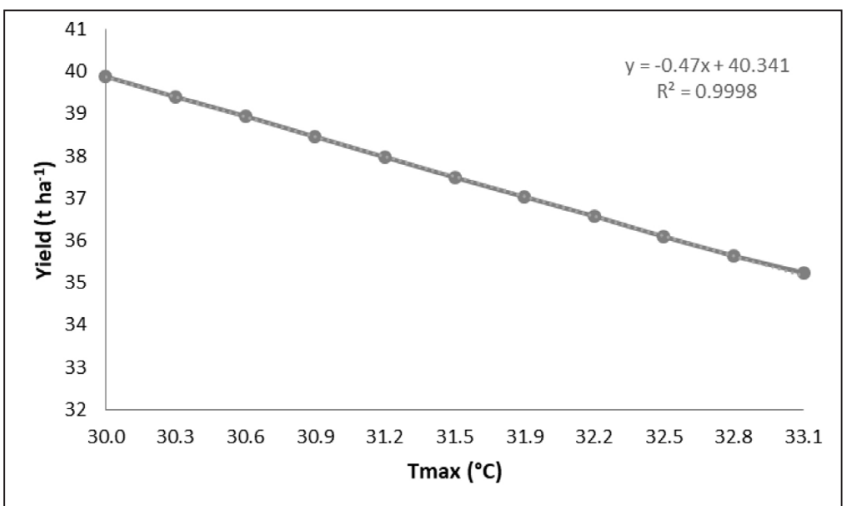

Fig. 2: Predicted yield of cassava with respect to the sensitivity of maximum temperature

between 0.81 to $1.36{ }^{\circ} \mathrm{C} /$ decade. However, no trend was observed in minimum temperature in the peninsular region in all the four seasons. Monthly trend analysis 
Table 4: Trend and decadal changes in monthly values of sunshine duration (hour/decade)

\begin{tabular}{|c|c|c|c|c|c|c|c|c|c|c|c|c|}
\hline Region & January & February & March & April & May & June & July & August & September & October & November & December \\
\hline Northeast & $\begin{array}{l}0.12 \\
(0.09) \\
0.45^{* *}\end{array}$ & $\begin{array}{l}0.12 \\
(0.09) \\
0.45^{* *}\end{array}$ & $\begin{array}{l}0.00 \\
(-0.03) \\
0.81^{* *}\end{array}$ & $\begin{array}{l}-0.31 \\
(-0.14) \\
0.26^{* *}\end{array}$ & $\begin{array}{l}-0.25 \\
(-0.71) \\
0.59^{* *}\end{array}$ & $\begin{array}{l}-0.93^{*} \\
(-0.32) \\
0.01^{* *}\end{array}$ & $\begin{array}{l}-0.59 \\
(-0.17) \\
0.19^{* *}\end{array}$ & $\begin{array}{l}-0.50 \\
(-0.22) \\
0.08^{* *}\end{array}$ & $\begin{array}{l}-0.09 \\
(-0.06) \\
0.66^{* *}\end{array}$ & $\begin{array}{l}-0.34 \\
(-0.24) \\
0.06^{* *}\end{array}$ & $\begin{array}{l}-0.12 \\
(-0.17) \\
0.18^{* *}\end{array}$ & $\begin{array}{l}0.16 \\
(0.19) \\
0.15^{* *}\end{array}$ \\
\hline Peninsular & $\begin{array}{l}0.06 \\
(-0.02) \\
0.87^{* *}\end{array}$ & $\begin{array}{l}0.03 \\
(0.01) \\
0.97^{* *}\end{array}$ & $\begin{array}{l}-0.03 \\
(-0.20) \\
0.12^{* *}\end{array}$ & $\begin{array}{l}-0.03 \\
(-0.22) \\
0.09^{* *}\end{array}$ & $\begin{array}{l}-0.12 \\
(-0.17) \\
0.19^{* *}\end{array}$ & $\begin{array}{l}-0.22 \\
-0.19) \\
0.14^{* *}\end{array}$ & $\begin{array}{l}-0.28^{*} \\
(-0.18) \\
0.16^{* *}\end{array}$ & $\begin{array}{l}0.06 \\
(0.05) \\
0.68^{* *}\end{array}$ & $\begin{array}{l}-0.12 \\
(-0.18) \\
0.16^{* *}\end{array}$ & $\begin{array}{l}-0.16^{*} \\
(-0.32) \\
0.01^{* *}\end{array}$ & $\begin{array}{l}-0.12 \\
(-0.16) \\
0.19^{* *}\end{array}$ & $\begin{array}{l}0.03 \\
(0.07) \\
0.56^{* *}\end{array}$ \\
\hline
\end{tabular}

* denotes trend at 5\% significance level using Mann-Kendall trend analysis where $\mathrm{p}<0.05$; value in bracket denotes the test statistic value obtained through MK test; ** denotes the p value obtained in the MK-test; '-' sign indicates decreasing trend. of maximum temperature (Table 3 ) in northeast region indicated a positive (increasing) trend with the highest value in September with a magnitude of $1.17^{\circ} \mathrm{C} /$ decade. A significant trend was detected in the $\mathrm{P}$ region for January and November with values of 0.84 and $0.59{ }^{\circ} \mathrm{C} /$ decade, respectively. Minimum temperature increased significantly in northeast region during the month of March, April, May, and July through December with the maximum trend during November with the magnitude of $1.58{ }^{\circ} \mathrm{C} /$ decade. Minimum temperature detected no trend in peninsular region for all twelve months. The monthly trends in the minimum and maximum temperatures can give the farmers vital information to adjust the crop's planting time to mitigate the heat stresses on the yield of cassava.

The seasonal trend analysis indicated a solar dimming over northeast India during summer, monsoon and autumn seasons (Figs. 3 \& 4). A significant declining trend was observed during monsoon and autumn seasons while using MK trend analysis. The rate of decline during the monsoon season has been about -0.53 hour/decade and during the autumn season, it was about -0.25 hour/ decade, respectively. The rate of dimming during the summer season was estimated as -0.19 hour/decade, also exhibiting the conformity of previous studies (Jhajharia et al., 2018a, b) undertaken for in northeast India. Similar to the northeast region, a dimming was also observed in the peninsular region during summer, autumn, and monsoon seasons, and the observed rate of dimming was around $-0.06,-0.16$, and -0.12 hour/decade, respectively. Sunshine brightening was observed during the winter season in the both the regions, though, these trends were not significant. The monthly trends have been presented in Table 4. The variability in sunshine duration during the monsoon season may be attributed to the huge amount of water vapour present in the atmosphere. This water vapour has enormous greenhouse effect, altering the entry of sunshine (Kumari and Goswami, 2010), consequently caused an increase in the day and night temperatures. The summer and autumn dimming may be attributed to the shallow and deeper clouds with large amount of aerosols formed by the human induced developmental activities such as industrialization, transportation and presence of larger sea salts (Liepert, 2002). However, the dimming or brightening directly influences the day and night-time temperatures and finally influences the crop growth and development ultimately the yield attributes.

\section{CONCLUSION}

An assessment of the meteorological sensitivity of the WOFOST model in simulating the yield of cassava has been carried out in one of the major cassava growing locations in India, followed by their trends over the major cassava growing areas across India. Cassava yield has been critically dependent on air temperature (minimum and maximum), followed by solar radiation. Increase in solar radiation causes a positive change (increase) in the crop yield and vice-versa. The yield fluctuation due to solar radiation varied between 2.07 to $-2.41 \%$ comparatively lesser then the yield variations due to temperature fluctuations. The decline or dimming in sunshine duration directly affected the maximum and minimum temperatures, and the trend is analyzed for all four seasons and 12 months. The scientific information thus generated from the study may further assist the decision-makers to develop appropriate plans to maximize the cassava's production to ensure food security up to certain extent. However, further studies are needed to identify the regional shifting of cassava or its suitability in the context of climate change and food security. 


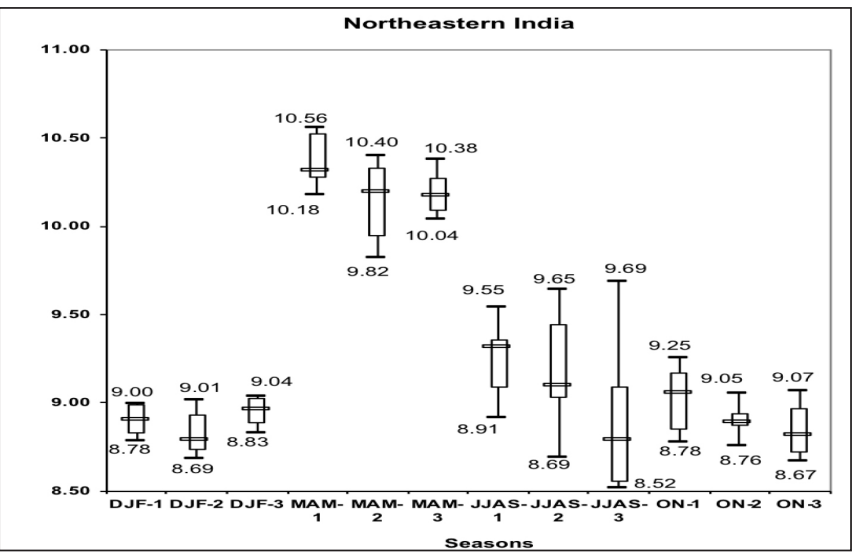

Fig. 3: Decadal variations in sunshine duration in all four seasons in northeast India

\section{ACKNOWLEDGEMENT}

Authors are thankful to Women Scientist Scheme, Department of Science \& Technology, India (DST WOS-A) and ICAR-Central Tuber Crops Research Institute (ICAR-CTCRI), Thiruvananthapuram, India for the complete support to execute this study.

Conflict of Interest Statement: The author(s) declare(s) that there is no conflict of interest.

Disclaimer: The contents, opinions, and views expressed in the research article published in the Journal of Agrometeorology are the views of the authors and do not necessarily reflect the views of the organizations they belong to.

Publisher's Note: The periodical remains neutral with regard to jurisdictional claims in published maps and institutional affiliations

\section{REFERENCES}

Borkakati, R.N., Saikia, D.K., and Venkatesh, M.R. (2021). Influence of meteorological parameters on population build-up of brinjal shoot and fruit borer, Leucinodes orbonalis Guenee in Assam. $J$. Agrometeorol., 23(2): 249-251.

Boogaard, H., Van Diepen, C., Rotter, R., Cabrera, J., and Van Laar, H. (1998). WOFOST 7.1; user's guide for the WOFOST 7.1 crop growth simulation model and WOFOST Control Center 1.50927-4499.

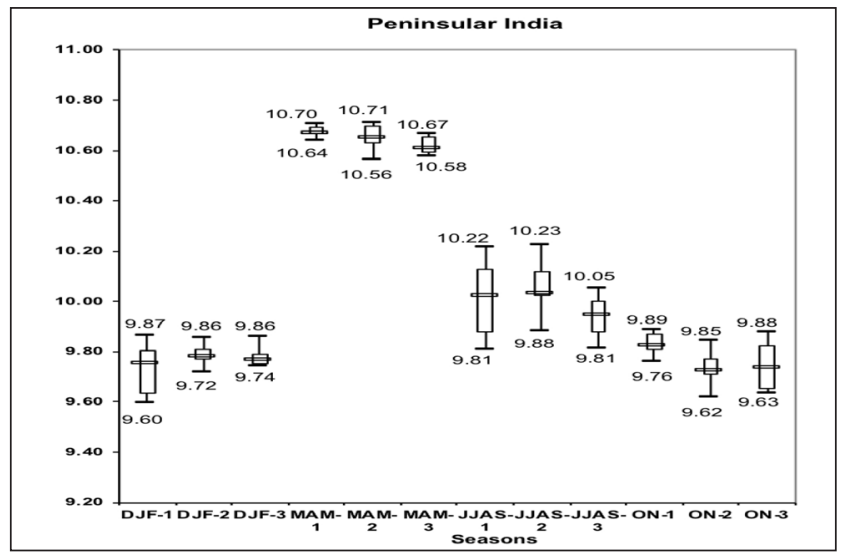

Fig. 4: Decadal variations in sunshine duration in all four seasons in northeast India

Byju, G., and Suja, G. (2020). Mineral nutrition of cassava. Adv. Agron., 159. https://doi.org/10.1016/ bs.agron.2019.08.005

Jhajharia, D., Pandey, P., Tapang, T., Laji, S., Dahal, K., Choudhary, R., and Kumar, R. (2018a). Trends in sunshine duration in humid climate of northeast India: A case study. Urban Ecol., Water Qual. Climate Change, Springer. 181-191.

Jhajharia, D., Pandey, P., Pandey, V., Dabral, P., Choudhary, R., Kumar, R., and Singh, V. (2018b). Changes in sunshine duration in humid environments of Agartala (Tripura), India. Climate Change Impacts, Springer. 15-24.

Kendall, M.G. (1975). Rank correlation methods, 4th edn. Charles Griffin, London.

Kumari, B.P., and Goswami, B.N. (2010). Seminal role of clouds on solar dimming over the Indian monsoon region. Geophysical Research Letters, 37: L06703. doi:10.1029/2009GL042133.

Liepert, B.G. (2002). Observed reductions of surface solar radiation at sites in the United States and worldwide from 1961 to 1990. Geophy. Res. Letters, 29(10): 1421. doi: 10.1029/2002GL014910.

Mann, H.B. (1945). Non-parametric tests against trend. Econometr. 33: 245-259.

Pushpalatha, R., and Byju, G. (2020). Is Cassava (Manihot esculenta Crantz) a Climate "Smart" Crop? A Review in the Context of Bridging Future 
Food Demand Gap. Trop. Plant Biol.. https://doi. org/10.1007/s12042-020-09255-2.

Pushpalatha, R., Shiny, R., Kutty, G., Dua, V.K., Sunitha, S., Santhosh Mithra, V.S., and Byju, G. (2021). Testing of cassava varieties for climate resilience under Kerala (India) conditions. Agril. Res. https:// doi.org/10.1007/s40003-021-00547-x.

Richtera GM, Acutisb M, Trevisiol P, Latiri K, and Confalonierib R. (2010). Sensitivity analysis for a complex crop model applied to Durum wheat in the Mediterranean. European J. Agron., 32: 127-136.

Singh, R.N., Sah, S., Chaturvedi, G., Das, B., and Pathak,
H. (2021). Innovative trend analysis of rainfall in relation to soybean productivity over western Maharshtra. J. Agrometeorol., 23(2): 228-235.

Sreenivas, A.G., Desai, B.K., Umesh, M.R., Usha, R., Sudharani, and Vijayalakshmi. (2021). Elevated $\mathrm{CO}_{2}$ and temperature effect on canopy development and seed yield of sunflower. J. Agrometeorol., 23(2): 264-267.

Zare, H., Fallah, M.H., Asadi, S., Mojab, A., and Bannayan, M. (2016). Assessment of DSSAT and WOFOST sensitivity to temperature derived from AgMERRA. International Crop Modelling Symposium, Icropm, March 15-17, Berlin, Germany. 